\title{
ACUTE DIETARY NITRATE SUPPLEMENTATION FAILS TO IMPROVE EXERCISE ECONOMY IN ELDERLY
}

\author{
M. Driller ${ }^{1}$, L. Thompson ${ }^{1}$, J. McQuillan ${ }^{1}$, R. Masters ${ }^{1,2}$
}

\begin{abstract}
Objective: Improvements in exercise economy following dietary nitrate $\left(\mathrm{NO}_{3}^{-}\right)$supplementation in young, athletic populations has been well documented, but little research has focused on whether these same benefits translate to elderly populations. Design: Participants completed two experimental trials in a double-blind, randomized, crossover design. Setting: University laboratory. Participants: Twenty-one elderly participants $>65$ yr (10 male/11 female, mean \pm SD; age: $72 \pm 6$ yr). Intervention: Each trial consisted of participants ingesting a $70 \mathrm{ml}$ dose of either $\mathrm{NO}_{3}^{-}$rich $\left(\mathrm{NIT}^{-} 5.0 \mathrm{mmol}^{-1}\right.$ ) or $\mathrm{NO}_{3}^{-}$depleted (PLA; $0.003 \mathrm{mmol}^{-1}$ ) beetroot juice two hours prior to reporting to the laboratory. Measurements: On arrival at the laboratory, blood pressure was assessed followed by a five minute walking economy test on a treadmill ( $3 \mathrm{~km} . \mathrm{h}-1$ and $1 \%$ gradient). VO ${ }^{\prime}$, heart rate and RPE were monitored during the walking test. Results: There were no significant differences $(\mathrm{p}>0.05)$ between NIT and PLA trials for any of the measured variables during the walking test. Furthermore, no differences were found for blood pressure between trials. All results were associated with trivial or unclear effect sizes. Conclusion: Despite recent reports of improved exercise economy in young, athletic populations following $\mathrm{NO}_{3}^{-}$supplementation, the current study did not find any benefit to submaximal $\mathrm{VO}_{2}$, heart rate, perceived exertion or blood pressure in elderly participants when performing a 5-minute walk following $\mathrm{NO}_{3}^{-}$supplementation.
\end{abstract}

Key words: Beetroot, exercise efficiency, $\mathrm{VO}_{2}$.

\section{Introduction}

Exercise performance improvements following dietary nitrate $\left(\mathrm{NO}_{3}^{-}\right)$supplementation in athletic and healthy young populations are well documented (1). Researchers have also documented improvements in sub-maximal exercise economy and decreases in resting blood pressure in these populations (2-4). However, while these effects have been thoroughly investigated in younger populations, research into the effects of $\mathrm{NO}_{3}^{-}$supplementation in elderly populations $(\geq 65 \mathrm{yr})$ is currently lacking.

To the authors' knowledge, there is only one published study evaluating the effect of $\mathrm{NO}_{3}^{-}$supplementation on blood pressure and exercise economy in elderly participants. Kelly et al. (5) studied the effect of three days of dietary $\mathrm{NO}_{3}^{-}$supplementation $\left(\sim 9 \mathrm{mmol}_{\text {.day }}{ }^{-1}\right)$ on the blood pressure, $\mathrm{O}_{2}$ uptake kinetics, and muscle and cognitive function of 12 older adults (mean age: 64 $\pm 4 \mathrm{yr}$ ). The authors concluded that the dietary nitrate supplementation reduced resting blood pressure and

1. University of Waikato, Hamilton, New Zealand; 2. School of Public Health, The University of Hong Kong, Hong Kong

Corresponding Author: Matthew Driller, University of Waikato, Hamilton, New Zealand, matt.driller@waikato.ac.nz

Received February 23, 2017

Accepted for publication March 29, 2017 improved $\mathrm{VO}_{2}$ kinetics during treadmill walking, but did not improve walking economy or cognitive performance. While these initial results yield positive findings, further research into $\mathrm{NO}_{3}^{-}$supplementation implementing different doses and investigating populations over 65 years of age is warranted.

The ageing process is associated with a number of functional and structural changes to the cardiovascular and muscular systems that may inhibit the mechanisms associated with $\mathrm{O}_{2}$ delivery and utilization during exercise (6). $\mathrm{NO}_{3}^{-}$supplementation, either in the form of sodium nitrate $\left(\mathrm{NaNO}_{3}\right)$ or beetroot juice, has been shown to significantly increase plasma nitrite $\left(\mathrm{NO}_{2}\right)$. $\mathrm{NO}_{2}^{-}$, which is synthesized in-vivo from $\mathrm{NO}_{3}^{-}$, is largely attributed to the mechanisms purported for the physiological enhancements associated with $\mathrm{NO}_{3}^{-}$supplementation (5). These purported mechanisms include vasodilation (7), increased $\mathrm{O}_{2}$ perfusion and delivery to working muscles (8) and increased mitochondrial efficiency (9). It is proposed that all of these factors may ultimately improve exercise economy, and thus aid daily task activities in older populations.

While the majority of exercise economy benefits are seen following chronic ( $\sim 3$ days) $\mathrm{NO}_{3}^{-}$dosing regimens (10), Vanhatalo et al. (4) reported that benefits to blood pressure and exercise economy were just as apparent 
following a single acute dose $\left(5.2 \mathrm{mmol} . \mathrm{L}^{-1} 2.5\right.$ hours prior to exercise), when compared to 5 and 15 days of supplementation in 8 healthy participants (mean age: 29 \pm 6 yr).

Therefore, the current study investigated the effect of an acute dose of concentrated beetroot juice $\left(5 \mathrm{mmol} . \mathrm{L}^{-1}\right.$ $\mathrm{NO}_{3}^{-}$) on exercise economy and blood pressure in an elderly population over 65 years of age.

\section{Materials and Methods}

\section{Participants}

Twenty-one participants $\geq 65 \mathrm{yr}$ volunteered to take part in the current study (10 male / 11 female, mean \pm SD; age: $72 \pm 6 \mathrm{yr}$; height: $169 \pm 10 \mathrm{~cm}$; body mass: $78 \pm 18 \mathrm{~kg}$ ). Participants all self-reported as healthy and active and were free from injury and medication (including blood pressure medication) that may have affected their ability to perform sub-maximal exercise. Participants were screened prior to participation to ensure their suitability for the study. Prior to inclusion, all participants were informed about the study including potential risks and benefits and were required to give written consent. This study was given ethical clearance by the Institution's Human Research Ethics Committee in accordance with the Helsinki declaration.

\section{Experimental design}

In a randomized, double-blind, crossover design, each participant performed two experimental trials separated by 7 days: nitrate (NIT) and placebo (PLA). All testing was performed at sea-level in controlled laboratory conditions $\left(21^{\circ} \mathrm{C}, 60 \%\right.$ relative humidity). Participants were asked to refrain from strenuous exercise $(<12$ hours) and to arrive at both testing sessions in a fully rested, hydrated state. Participants were also instructed to refrain from caffeine ( $<12$ hours), to arrive two hours post-prandial and to avoid using mouthwash or spitting during the intervention, as both actions have been associated with lowering of basal $\mathrm{NO}_{2}^{-}$(11). To control for biological variation, participants reported for testing at the same time of day on both occasions ( \pm 1 hour). The participants were instructed to follow their normal dietary habits throughout the experimental period and to record and replicate their diet as closely as possible in the 24-hours leading up to both testing sessions.

\section{Supplementation}

Each trial consisted of participants ingesting a $70 \mathrm{ml}$ dose of either $\mathrm{NO}_{3}^{-}$rich (NIT) [5.0mmol. $\left.\mathrm{L}^{-1}\right]$ or $\mathrm{NO}_{3}^{-}$depleted (PLA) $\left[0.003 \mathrm{mmol}^{-1} \mathrm{~L}^{-1}\right.$ beetroot juice two hours prior to arrival at the laboratory. The timing and concentration is consistent with previous
$\mathrm{NO}_{3}^{-}$supplementation related studies investigating effects on health parameters $(4,12)$. The NIT and PLA supplements were sourced from the same manufacturer (Beet it, James White Drinks, Ipswich, UK). The PLA supplement was similar to NIT in appearance, taste and smell and was created by passage of the juice, before pasteurization, through a column containing Purolite A520E ion exchange resin, which selectively removes $\mathrm{NO}_{3}^{-}$ions, as described previously (13). Participants were informed that a possible short-term, harmless side effect from this supplementation was beeturia (red urine) and red stools. A between-trial wash-out period of 72 hours has been deemed appropriate following acute nitrate supplementation (5); however, we opted for one week between trials in the current study.

\section{Blood pressure}

Following arrival at the laboratory, blood pressure (BP) was assessed using an automatic sphygmomanometer (Omron Healthcare, Hoofddorp, Netherlands), with participants in a seated position after ten minutes of passive rest. Three measurements were taken with the recorded value being the mean of the final two measurements.

\section{Walking economy test}

Immediately following BP measurement, participants performed a 5-minute sub-maximal walking test at $3 \mathrm{~km} \cdot \mathrm{h}^{-1}$ at a $1 \%$ incline on a motorized treadmill (HP Cosmos, h/p/cosmos Sports \& Medical GmbH; Traunstein, Germany). During the test, heart rate (Polar Electro Oy, Kempele, Finland) and oxygen consumption were recorded continuously with rate of perceived exertion (Borg's 6-20 RPE scale) recorded every minute. Oxygen consumption was measured via expired gas variables collected into a mixing chamber and analysed at 15-s intervals throughout the walking test using a metabolic cart (TrueOne 2400, Parvo Medics, Inc., Utah, USA). Participants were required to wear a nose clip and breath through a mouthpiece that was attached to the metabolic cart for the entire walking test. The metabolic cart was calibrated prior to each test using gases of known concentrations, as per the manufacturer's instructions. The final $30 \mathrm{~s}$ of the walk was averaged to interpret effects for $\mathrm{NO}_{3}^{-}$on exercise economy via analysis of absolute (L.min ${ }^{-1}$ ) and relative (mL.kg. $\left.{ }^{-1} \mathrm{~min}^{-1}\right) \mathrm{VO}_{2}(13)$.

\section{Statistical Analysis}

Simple group statistics are shown as means \pm standard deviations unless stated otherwise. A student's paired T-test was used to compare both trials for all measures using a Statistical Package for Social Science (V. 22.0, SPSS Inc., Chicago, IL), with statistical significance set at 
Table 1

Mean \pm SD values for the measured variables during the walking test following placebo (PLA) and nitrate (NIT) supplementation, including the absolute difference between trials, p-values and Effect Sizes $( \pm 90 \%$ confidence intervals)

\begin{tabular}{lccccc}
\hline & PLA & NIT & $\begin{array}{c}\text { Absolute } \\
\text { Difference } \\
\text { (NIT - PLA) }\end{array}$ & p-value & $\begin{array}{c}\text { NIT - PLA } \\
\text { Effect Size } \\
( \pm 90 \% \text { Confidence } \\
\text { Intervals) }\end{array}$ \\
\hline Economy $\left(\mathrm{VO}_{2}\right.$ - L.min $\left.{ }^{-1}\right)$ & $0.85 \pm 0.23$ & $0.87 \pm 0.22$ & $0.02 \pm 0.12$ & 0.42 & $\begin{array}{c}0.07 \pm 0.20 \\
\text { Trivial }\end{array}$ \\
Economy $\left(\mathrm{VO}_{2}-\mathrm{mL} \cdot \mathrm{kg} \cdot{ }^{-1} \mathrm{~min}^{-1}\right)$ & $12.81 \pm 1.74$ & $13.11 \pm 2.59$ & $0.30 \pm 2.00$ & 0.49 & $\begin{array}{c}0.17 \pm 0.42 \\
\text { Unclear } \\
0.09 \pm 0.20 \\
\text { Trivial }\end{array}$ \\
Mean Heart Rate (bpm) & $93 \pm 15$ & $95 \pm 15$ & $2 \pm 8$ & 0.45 & $0.14 \pm 0.38$ \\
Mean RPE (AU) & $7.2 \pm 1.8$ & $7.5 \pm 1.6$ & $0.3 \pm 1.7$ & 0.53 & \begin{tabular}{c} 
Unclear \\
\hline
\end{tabular} \\
\hline
\end{tabular}

Table 2

Mean \pm SD values for blood pressure (BP) variables following placebo (PLA) and nitrate (NIT) supplementation, including the absolute difference between trials, p-values and Effect Sizes ( $\pm 90 \%$ confidence intervals). SYS BP $=$ systolic blood pressure, DIAS BP = diastolic blood pressure

\begin{tabular}{lccccc}
\hline PLA & NIT & $\begin{array}{c}\text { Absolute Difference } \\
\text { NIT - PLA }\end{array}$ & p-value & $\begin{array}{c}\text { (NIT - PLA) } \\
\text { Effect Size } \\
\mathbf{\pm 9 0 \%} \text { Confidence } \\
\text { Intervals) }\end{array}$ \\
\hline SYS BP (mmHg) & $137 \pm 20$ & $135 \pm 19$ & $-2 \pm 13$ & 0.55 & $-0.08 \pm 0.24$ \\
Trivial \\
DIAS BP (mmHg)
\end{tabular}

$p<0.05$. There were no outliers in the data, as assessed by inspection of a boxplot. Scores for all measured variables were normally distributed, as assessed by Shapiro-Wilk's test $(p>0.05)$, and there was homogeneity of variances between trials, as assessed by Levene's test for equality of variances $(p>0.05)$. Cohen's effect sizes $(d)$ were calculated between NIT and PLA trials and interpreted using thresholds of 0.2, 0.5, 0.8 for small, moderate and large sizes, respectively (14). An effect size of $<0.2$ was considered to be trivial and the effect was deemed unclear if its $90 \%$ confidence interval overlapped the thresholds for small positive and negative effects $( \pm 0.2)(15)$.

\section{Results}

Results for exercise economy, heart rate and RPE during the walking test were not significantly different between NIT and PLA trials ( $p>0.05$, Table 1$)$. The difference between trials for all measured variables resulted in either trivial or unclear effect sizes.

There were no significant differences between trials for either systolic or diastolic blood pressure $(\mathrm{p}>0.05$, Table 2).

\section{Discussion}

The main finding in the current study was that a single acute dose of $\mathrm{NO}_{3}^{-}$via concentrated beetroot juice failed to improve exercise economy or lower blood pressure in an elderly population $>65 \mathrm{yr}$. This is the first study to assess the effect of an acute $\mathrm{NO}_{3}{ }^{-}$dose in elderly participants and contrasts the findings found in a similar population following a chronic dose of $\mathrm{NO}_{3}^{-}$(5). The finding also contrasts with reported improvements in exercise economy and blood pressure in younger adults following a similar dosing regimen (4).

It is postulated that the $\mathrm{NO}_{3}^{-}$dose used in the current study (a single $70 \mathrm{ml}$ shot of concentrated beetroot juice) may not have been adequate to elicit changes in $\mathrm{NO}_{2}^{-}$ levels in our participants, and therefore failed to influence the physiological mechanisms that have been associated with NO3- mediated improvements. Indeed, the only 
other study in an elderly population by Kelly et al. (5) utilized $140 \mathrm{ml}\left(\sim 9.6 \mathrm{mmol} . \mathrm{L}^{-1} \mathrm{NO}_{3}^{-}\right)$daily for 3 days. The higher overall dose used in their study led to significantly lower blood pressure and a faster $\mathrm{VO}_{2}$ response time when compared to placebo ( $p<0.05)$. However, similar to the current study, Kelly et al. (5) found no differences in the $\mathrm{O}_{2}$ cost during sub-maximal exercise (incremental treadmill walking) following $\mathrm{NO}_{3}^{-}$. Vanhatolo et al. (4), however, reported that acute, moderate and longer term $\mathrm{NO}_{3}{ }^{-}$supplementation reduced blood pressure and improved exercise economy in a younger population (29 $\pm 6 \mathrm{yr}$ ). Notably, the duration of the supplementation period used by Vanhatolo et al. (4) did not appear to influence the degree of improvement in either measure, suggesting that acute dosing strategies are as effective as longer-term ( $~ 15$ days) strategies for improving blood pressure and exercise economy measures in young recreational populations.

Biological aging is associated with loss of fast-twitch muscle fibres, so given that a number of $\mathrm{NO}_{3}^{-}$related enhancements favor fast-, but not slow-twitch muscle (16), it is likely that one or a combination of trial intensity, age and relative fitness levels of the current population may have resulted in the negligible effects observed for economy following $\mathrm{NO}_{3}^{-}$supplementation. Indeed, the present population recorded an average RPE rating of 'extremely light' exercise intensity. As such, the intensity of the walk in the current study was unlikely to improve the biogenesis of NO under the exercise conditions.

A limitation of the current study was that basal plasma $\left[\mathrm{NO}_{2}^{-}\right]$levels were not measured, making it difficult to ascertain whether the dose used was enough to cause any physiological perturbations. Future research should investigate the dose-response relationship of $\mathrm{NO}_{3}^{-}$for altering plasma $\mathrm{NO}_{2}^{-}$levels and blood pressure in elderly populations $>65 \mathrm{yr}$. Other areas of future research may also include the performance effects of $\mathrm{NO}_{3}{ }^{-}$in elderly athletes. It is yet to be determined whether the same performance benefits seen in younger athletes (1) may be realized in an older athletic population.

In conclusion, an acute dose of concentrated beetroot juice taken 2 hours prior to sub-maximal exercise, failed to influence exercise economy or blood pressure in elderly participants when compared to a placebo trial. The lack of effect on these measures may be due to the low acute dose used; however, until a dose-response relationship is established in an elderly population, this is speculation.

Ethical Standards: The current experiment complies with the laws of the country in which they were performed. The institutions Human Research Ethics committee granted ethical approval.

Conflict of interest: None.

\section{References}

1. Jones AM. Dietary nitrate supplementation and exercise performance. Sports Med 2014;44 (1):35-45

2. Bailey SJ, Winyard P, Vanhatalo A, Blackwell JR, DiMenna FJ, Wilkerson DP, Tarr J, Benjamin N, Jones AM. Dietary nitrate supplementation reduces the $\mathrm{O} 2$ cost of low-intensity exercise and enhances tolerance to high-intensity exercise in humans. J Appl Physiol 2009;107 (4):1144-1155

3. Larsen FJ, Ekblom B, Sahlin K, Lundberg JO, Weitzberg E. Effects of dietary nitrate on blood pressure in healthy volunteers. N Eng J Med 2006;355 (26):2792-2793

4. Vanhatalo A, Bailey SJ, Blackwell JR, DiMenna FJ, Pavey TG, Wilkerson DP, Benjamin N, Winyard PG, Jones AM. Acute and chronic effects of dietary nitrate supplementation on blood pressure and the physiological responses to moderate-intensity and incremental exercise. Am J Physiol Regul Integr Comp Physiol 2010;299 (4):R1121-R1131

5. Kelly J, Fulford J, Vanhatalo A, Blackwell JR, French O, Bailey SJ, Gilchrist M, Winyard PG, Jones AM. Effects of short-term dietary nitrate supplementation on blood pressure, $\mathrm{O} 2$ uptake kinetics, and muscle and cognitive function in older adults. Am J Physiol Regul Integr Comp Physiol 2013;304 (2):R73-R83

6. Borges N, Reaburn P, Driller M, Argus C. Age-related changes in performance and recovery kinetics in masters athletes: a narrative review. J Aging Phys Act 2016;24 (1):149-157

7. Webb AJ, Patel N, Loukogeorgakis S, Okorie M, Aboud Z, Misra S, Rashid R, Miall P, Deanfield J, Benjamin N. Acute blood pressure lowering, vasoprotective, and antiplatelet properties of dietary nitrate via bioconversion to nitrite. Hypertension 2008;51 (3):784-790

8. Vanhatalo A, Fulford J, Bailey SJ, Blackwell JR, Winyard PG, Jones AM. Dietary nitrate reduces muscle metabolic perturbation and improves exercise tolerance in hypoxia. J of Phys 2011;589 (22):5517-5528

9. Larsen FJ, Schiffer TA, Borniquel S, Sahlin K, Ekblom B, Lundberg JO, Weitzberg E. Dietary inorganic nitrate improves mitochondrial efficiency in humans. Cell Metab 2011;13 (2):149-159

10. Hoon MW, Johnson NA, Chapman PG, Burke LM. The effect of nitrate supplementation on exercise performance in healthy individuals: a systematic review and meta-analysis. Int J Sport Nutr Ex Met 2013;23 (5):522-532

11. Govoni M, Jansson EÅ, Weitzberg E, LundbergJO. The increase in plasma nitrite after a dietary nitrate load is markedly attenuated by an antibacterial mouthwash. Nitric Oxide 2008;19 (4):333-337

12. Webb AJ, Patel N, Loukogerorgakis S, Okorie M, Aboud Z, Misra S, Rashid R, Miall P, Deanfield J, Benjamin N, MacAllister R, Hobbs AJ, Ahluwalia A. Acute blood pressure lowering, vasoprotective, and anitplatelet properties of dietary nitrate via bioconversion to nitrate. Hypertension 2008;51 (3):784 - 790

13. Lansley KE, Winyard PG, Fulford J, Vanhatalo A, Bailey SJ, Blackwell JR, DiMenna FJ, Gilchrist M, Benjamin N, Jones AM. Dietary nitrate supplementation reduces the $\mathrm{O} 2$ cost of walking and running: a placebocontrolled study. J Appl Physiol 2011;110 (3):591-600

14. Cohen J. Statistical power analysis for the behavioral sciences. Lawrence Erlbaum, Hillsdale, NJ, 1988.

15. Batterham A, Hopkins W. Making meaningful inferences about magnitudes Int J Sports Physiol Perform 2006;1 (50):50-57

16. Jones AM, Ferguson SK, Bailey SJ, Vanhatalo A, Poole DC. Fiber type-specific effects of dietary nitrate. Exerc Sport Sci Rev 2016;44 (2):53-60 